\title{
COMPARISON OF DIFFERENT METHODS FOR THE OCCLUSAL DENTINE CARIES DIAGNOSIS*
}

\author{
COMPARAÇÃO DE DIFERENTES MÉTODOS DE DIAGNÓSTICO \\ DA LESÃO DE CÁRIE OCLUSAL EM DENTINA
}

Soraya Fernandes MESTRINER ${ }^{1}$, Dionísio VINHA ${ }^{2}$, Wilson MESTRINER JUNIOR ${ }^{3}$

*Part of a thesis presented to Ribeirão Preto School of Dentistry - University of São Paulo for a Master's Degree in Oral Rehabilitation.

1- Professor of courses of Preventive and Sanitary Dentistry and Supervised Training at University of Franca (UNIFRAN).

2- Full Professor of Department of Restorative Dentistry of Ribeirão Preto School of Dentistry - University of São Paulo.

3- Associate Professor of Department Child Clinic and Social Dentistry of Ribeirão Preto School of Dentistry- University of São Paulo.

Corresponding address: Wilson Mestriner Júnior - Telefone: (016) 6205179 / (016) 91181104 - Fax: (016) 6330999

Av do Café s/nº Faculdade de Odontologia de Ribeirão Preto - USP - E-mail: mestri@forp.usp.br

Received: December 12, 2003 - Modification: April 14, 2004 - Accepted: October 11, 2004

\begin{abstract}
$T$

he aim of this study was to compare the effectiveness of in-vitro methods for the occlusal dentine caries diagnosis. Thirtyeight sites were evaluated on third molars without macroscopic carious cavitation in adult individuals from the city of Barretos (SP), Brazil. Visual inspection (VI), endoscopic evaluation (AcuCam), visual inspection and blunt-tipped exploratory probes (Tactile), conventional bite-wing radiographs (CR), direct bite-wing digital radiograph (DR), and direct digital radiograph with contrast and brightness controled (DRbc) were used by five observers. In order to validate the data, the teeth were sectioned and histologically evaluated. The average sensitivity and specificity values of the methods were respectively:0,25 , 0,96 (VI); 0,15 , 0,92 (AcuCam); 0,17 , 0,95 (Tactile); 0,45 , 0,73 (CR); 0,33 , 0,80 (DR) and 0,35 , 0,84 (DRbc), the effectiveness of clinical methods (VI, AcuCam and Tactile) as well as that of radiographic methods (CR, DR and DRbc) were comparatively similar. The clinical methods presented a smaller number of false-positive diagnosis than the radiographic methods. It was concluded that visual inspection is an important diagnostic method; conventional bite-wing and digital radiography aid the diagnosis and are equally efficient to diagnose carious lesions in the dentine of teeth without visible cavitation.

Uniterms: Dental caries; Occlusal surface,diagnosis; Dentine; Radiograph.
\end{abstract}

\section{RESUMO}

$O$

objetivo deste estudo foi comparar, in vitro, a efetividade de métodos de diagnóstico de lesões de cáries oclusais em dentina. Foram avaliados 38 sítios em $3^{\circ}$ molares sem cavidades macroscópicas, de indivíduos adultos, provenientes da cidade de Barretos. Os exames inspeção visual (IV), endoscópio (AcuCam), inspeção visual e uso de sonda exploradora de ponta romba (Táctil), radiografia interproximal (RxC), radiografia digital direta $(\mathrm{RxD})$, e radiografia digital direta com manipulação do contraste e brilho (Rxcb), foram realizados por 5 examinadores não calibrados. Para validação dos dados os dentes foram seccionados e avaliados histologicamente. Concluiu-se que, comparativamente, a efetividade entre os métodos clínicos foram similares, tanto quanto entre os radiográficos. Os métodos clínicos apresentaram um menor número de diagnósticos falsos positivos do que os radiográficos.

Unitermos: Cárie dentária; Superfície oclusal, diagnóstico; Dentina; Radiografia.

\section{INTRODUCTION}

Tooth enamel microporosity is the first sign of coronal caries. It can be viewed after the tooth surface is carefully dried. It consists in a slow demineralization process that can be reversed as long as caries does not occur ${ }^{12}$.
The selection of an appropriate treatment depends on a careful diagnosis of the clinical severity of dental caries ; however, such diagnosis is difficult to be achieved ${ }^{2}$, especially in the absence of cavitaties ${ }^{14}$, and particularly in populations with low caries prevalence ${ }^{24}$.

In many Western countries, the decline in the incidence 
of carious lesions has been accompanied by changes in lesion patterns and development. Epidemiological studies have detected that carious lesions without visible cavities are more prevalent than those with $\mathrm{it}^{3}$.

To Weerheijm, et al. ${ }^{25}$ (1989), if caries development is undetected, it means that usual diagnostic methods - visual inspection associated with tactile inspection or not - are faulty. In their opinion, bite-wing radiography must be used for diagnosis of hidden caries.

Probing showed to be inefficient when used with visual inspection, as both methods have been considered to be uncertain ${ }^{18,22}$. Additionally, probing is an invasive procedure $^{5,6}$ that transmits cariogenic microorganisms to other teeth within the same oral cavity.

The intraoral video camera (endoscope) was described by Pitts, Longbottom ${ }^{21}$, in 1987 , as a new and potentially sensitive diagnostic method to detect carious lesions due to its image magnification, which enhances viewing.

According to Ricketts, et al. ${ }^{22}$ (1995), bite-wing radiography showed to be the most accurate method for detection of carious and infected dentin.

As technology increasingly develops, conventional dental radiography is being replaced by digital radiography ${ }^{28}$, in which images can be manipulated and enlarged, in addition to environmental advantages such as the reduced use of chemical products and lower radiation doses.

The aim of this work is to comparatively evaluate the effectiveness of some in vitro methods for detection of dentinal occlusal carious lesions on teeth without macroscopic cavities, so that the preventive procedures can be conducted during treatment.

\section{MATERIALAND METHODS}

Thirty-eight third molars to be extracted for orthodontic reasons were selected from a group of thirty-six adult individuals of both genders aged 17 to 31 years old, who were born and raised in the city of Barretos (SP), Brazil, where regular levels of fluoride have been added to the water supply ${ }^{19}$ for more than 25 years. Such individuals also used fluoridated dentifrice three times a day in the average. After extraction, the teeth were stored in identified flasks containing a $3 \%$ formaldehyde solution. The teeth were anatomically similar to the first or second permanent molars. They presented at least one site on the occlusal surface showing a stained or pigmented fissure or pit without visible cavity upon visual inspection. After the teeth were cleaned by bicarbonate jet and water, thirty-eight sites of interest were marked on their occlusal aspects.

The teeth were assembled in a standardized fashion, one by one, in PVC rings measuring $1 / 2$ inch using condensation silicone (3M). Throughout the study, they were hydrated with saline solution, and only during evaluations were they removed and dried. Evaluations were conducted by 5 observers, who used 6 methods for diagnostic suggestions. All the methods were applied by all examiners at weekly intervals for assessment of each method.

In order to produce examination sheets, all occlusal aspects were photographed, thus generating $3 \mathrm{~cm} \times 5 \mathrm{~cm}$ images. These photos were photocopied as there was a specific sheet for each examination. Also, for each examination type, the teeth were given different sequential numbers so as not to induce the examiner to reach the same diagnosis as the one of the previous examination.

The diagnostic methods used are described as follows.

\section{Visual Inspection (VI)}

The mapped sites (Figure 1) were dried, illuminated and inspected by the naked eye. The diagnosis for each site was recorded on an individual site, which was exclusive for each examiner. The following criteria, as adapted from Lussi ${ }^{18}$ (1991), were used: 0 - absence of carious lesion; 1 - carious lesion in superficial enamel; 2 - carious lesion in deep enamel; 3 - carious lesion in dentin without pulpal injury; 4 - carious lesion in dentin with pulpal injury.

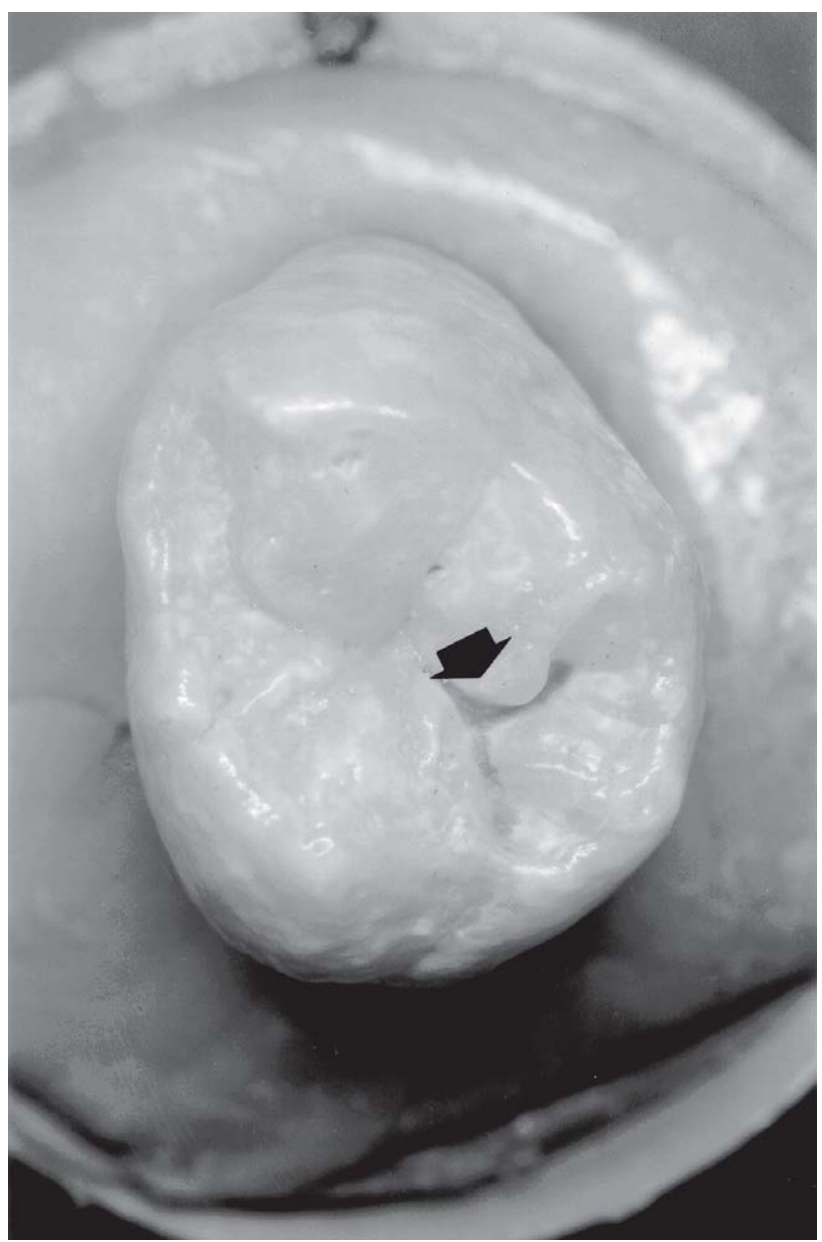

FIGURE 1- Macroscopic aspect of site (arrow) of the occlusal surface of a third molar evaluated by visual inspection, visual inspection and blunt-tipped probes (Tactile), endoscopic evaluation (AccuCam), conventional bite-wing $(\mathrm{RxC})$, direct bite-wing digital radiography $(\mathrm{R} \times \mathrm{D})$ and direct digital radiography with contrast and brightness control (Rxcb) method 


\section{Videoscope (ACCUCAM)}

An intraoral microcamera featuring the AccuCam PC 2000 system (New Image do Brasil), with its own fiber optics illumination system and fixed on a support upon a photographic table (Pentax), was used to obtain the images. As the teeth were always positioned in the same place, a distance of 15 millimeters was standardized between the microcamera and the occlusal surfaces of the teeth. Such surfaces were dried and the images generated with a magnification of 23 times were captured on a 14-inch color television set. The examiners analyzed the images and recorded their diagnoses on individual sheets. The recording criteria and values were the same as those used for visual inspection.

\section{Visual inspection by a blunt-tipped exploratory probe (tactile)}

Visual examinations were conducted with aid of a number5 blunt-tipped $(0.5 \mathrm{~mm}$ ) probe (Duflex). The examiners should not exert pressure during evaluation and the probe was to be used in an inclined position, softly sliding on the cusp edges. The diagnoses were recorded by following the same criteria as those of visual inspection.

\section{Conventional bite-wing radiography (CR)}

Channels were standardized on the PVC rings and fixation silicone by using metal saws. They were parallel to the teeth long axes in order to accommodate the radiographic film. Such channels enabled standardization of film (Kodak) and sensor positioning in order to obtain digital images. The X-ray source used was generated by $70 \mathrm{kvp}$ and $8 \mathrm{~mA}$ equipment (Dabi Atlante).

The tooth-bearing rings were positioned on a plaster support with a central fitting, which enabled a standardized positioning . The parallelism technique was applied for radiographic takings at a focus-film distance of 25 centimeters. The exposure time was of 0.5 second. The films were automatically developed (Morita).

The sites were evaluated by interpreting the radiographs on a negatoscope featuring a magnifying lens (3x) and a mask. The diagnosis for each site was recorded on the sheets according to the following criteria: 0 - without radiolucency; 1 - radiolucency on enamel without reaching EDJ; 2radiolucency involving EDJ up to $1 / 2$ of the dentin; 3 radiolucency involving more than $1 / 2$ of the dentin (without pulpal injury); 4 - radiolucency involving more than $1 / 2$ of the dentin (with pulpal injury).

\section{Direct digital radiography (DR)}

The Digora (Orion Soredex) digital reading system was used. Optical plates from the Digora direct imaging system with a regular size (adult), measuring 35x45x1.6 millimeters and image area of 30x40 millimeters and a protective packing were utilized. The exposure time was 0.3 second. The sensitized plates were placed on the Digora's optical reader, the images were exhibited and filed on the monitor.

The examiners were advised to use a standardized guide in order to use Digora by following the ordinal order of the sites on the diagnostic sheets.

\section{Digital radiography with contrast and brightness control (DRcb)}

Next, the diagnosis was obtained after individual adjustment of contrast and brightness scales, which was performed by the examiners themselves. The diagnostic criteria and recorded scores were the same as those used during conventional radiographic assessment.

\section{Histological evaluations}

Once all previous examinations had been conducted, the crowns were buccally-lingually sectioned, including the sites to be observed. The sections were performed by diamond discs on Minitrom (Struers) cutting equipment, and 600- to 800- $\mu \mathrm{m}$ slices were obtained and measured by a digital Digimatic (Mitutoyo) caliper. The sections were submitted to sequential wearing using from 300- to 600-grit sandpaper, which produced final sections of 100 to $200 \mu \mathrm{m}$.

The histological sections were individually placed on glass slides, soaked in distilled water and covered with coverslips. They were then examined on a Jenaval (Carl Zeiss) microscope under conventional and polarized lighting using an 3.2 x (GF- Planachromat) objective lens.

The sites were macroscopically and microscopically photographed (Figures 1 and 2). The criteria proposed by Deery, et al. ${ }^{4}$ (1995) were adopted for histological examination: 0 - without demineralization - without caries; 1 demineralization on superficial enamel (up to the external half of the enamel) - caries in superficial enamel; 2 demineralization on deeper enamel (more than the internal half of the enamel without involving the dentinoenamel junction) - caries in deep enamel; 3 - demineralization on the dentinoenamel junction and up to the external half of the dentin - dentinal caries. 4 - demineralization involving the internal half of the dentin - dentinal caries.

\section{STATISTICALANALYSIS}

The statistical analysis was performed by the GMC Basic Software, version 7.6. The sensitivity and specificity values of the methods comprised the variable; the methods used, the variation factor and the examiners constituted the repetitions.

Considering that the distribution of the sampling data was not normal and that the samples were dependent, multiple comparisons and the Friedman test were used. 


\section{RESULTS}

According to the results obtained from the histological evaluation, the prevalence of carious lesions was $32 \%$ in dentin and $55 \%$ in enamel, whereas $13 \%$ of the sites were healthy. Table 1 contains the sensitivity and specificity values of the methods used for each observer and their

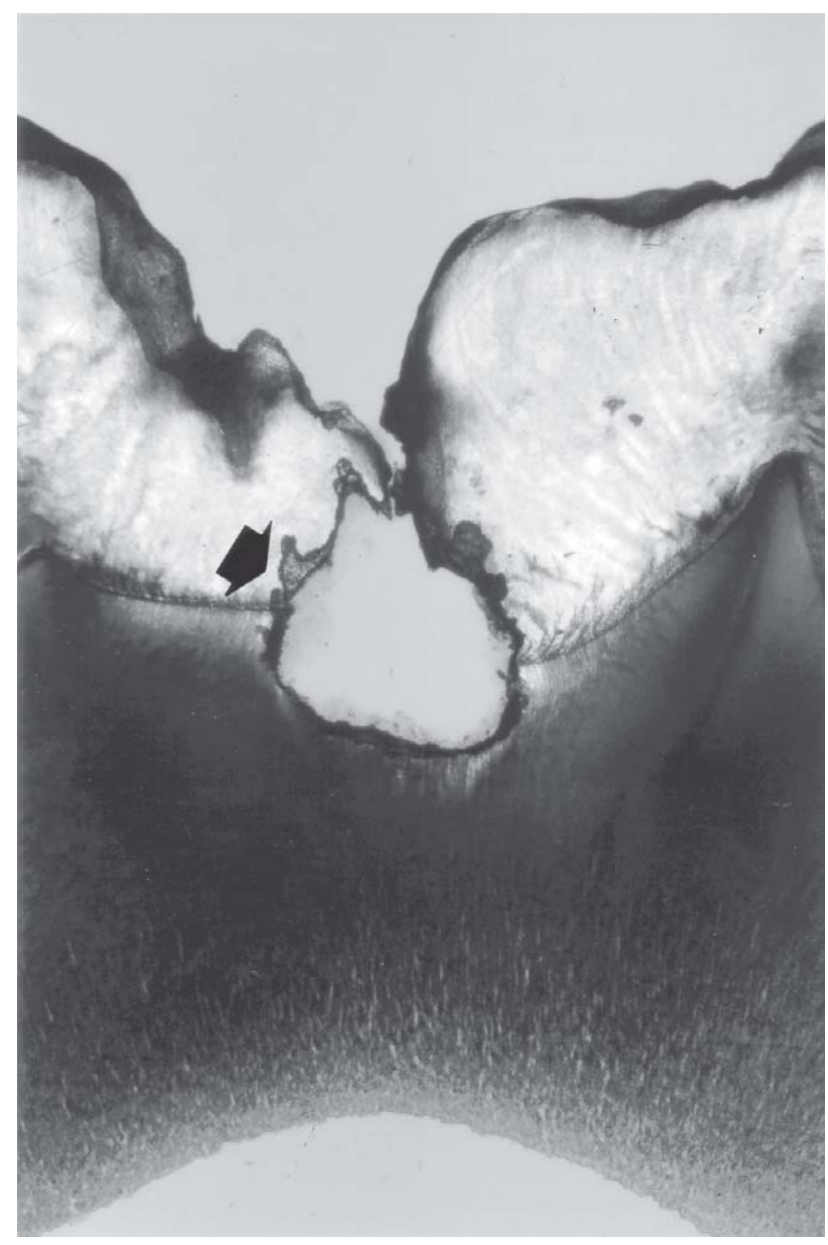

FIGURE 2- Photomicrography (polarized light) of site (arrow) showing the presence of dentinal caries averages. (LOCAL TABLE 01)

As to sensitivity, the different methods did not present statistically significant differences, that is, the number of sites with carious lesions in dentin in which the method was positive is similar for most methods, except for AccuCam and Tactile, which were significantly lower than CR at the $5 \%$ level .

Regarding specificity, when the clinical methods, that is, visual inspection, AccuCam and Tactile, were compared to one another, they behaved similarly, i.e. they did not show statistically significant differences, with means of 0.96, 0.92 and 0.95 respectively. However, the radiographic methods obtained specificity, that is, similar correct results regarding the absence of dental carious lesions, non-statistically significant differences with means of $0.72,0.80$ and 0.84 for CR, DR and DRcb, respectively. Nevertheless, they presented lower results than those of visual inspection, which were statistically significant to the level of $1 \%$ for CR and DRcb and $0.01 \%$ for DR. The AccuCam method was significantly superior to IV and CR at the 5\% level and to DR at the $1 \%$ level, presenting similar results to those of DRcb. The Tactile method was significantly superior to IV and DR at the 5\% level and similar to CR and DRcb.

Inter-observer agreement concerning Visual Inspection, AccuCam, Tactile, conventional bite-wing radiography and digital radiography, with and without manipulation of contrast and brightness, was expressed in Cohen’s Kappa. The calculated kappa was $0.22 ; 0.21 ; 0.23 ; 0.45 ; 0.39$ and 0.34 , respectively. These values are considered an agreement average $^{15}$.

\section{DISCUSSION}

The change in epidemiological and morphological models, as well as in the philosophy of treatment of dental caries, has encouraged attempts towards the improvement of existing diagnostic methods and the development of new ones. Many studies have been conducted to evaluate methods for occlusal caries diagnosis ${ }^{6,17,18,22,23,24}$. The results

TABLE 1- Sensitivity (S) and specificity (Sp) values and mean of the diagnostic methods, visual inspection (VI), visual inspection and blunt-tipped exploratory probes (Tactile), endoscopic evaluation (AccuCam), conventional bite-wing (CR), direct bite-wing digital radiography (DR) and direct digital radiography with contrast and brightness control (DRbc) obtained by observers $1,2,3,4$ and 5 , when utilizing the diagnostic methods for dentinal carious lesions in thirty-eight sites on third molars

\begin{tabular}{|c|c|c|c|c|c|c|c|c|c|c|c|c|}
\hline \multirow[t]{2}{*}{ Observers } & \multicolumn{2}{|c|}{ VI } & \multicolumn{2}{|c|}{ ACCUCAM } & \multicolumn{2}{|c|}{ TACTILE } & \multicolumn{2}{|c|}{ CR } & \multicolumn{2}{|c|}{ DR } & \multicolumn{2}{|c|}{ DRbc } \\
\hline & $\mathbf{S}$ & Sp & $\mathbf{S}$ & Sp & $S$ & Sp & 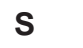 & Sp & $\mathbf{S}$ & Sp & $\mathbf{S}$ & Sp \\
\hline 1 & 0.33 & 0.92 & 0 & 0.96 & 0 & 1 & 0.33 & 0.88 & 0.16 & 0.88 & 0.16 & 0.88 \\
\hline 2 & 0.58 & 0.96 & 0.41 & 0.76 & 0.50 & 0.88 & 0.33 & 0.80 & 0.33 & 0.76 & 0.33 & 0.88 \\
\hline 3 & 0 & 1 & 0 & 1 & 0 & 1 & 0.50 & 0.84 & 0.41 & 0.69 & 0.41 & 0.73 \\
\hline 4 & 0.33 & 0.92 & 0.33 & 0.88 & 0.33 & 0.88 & 0.75 & 0.19 & 0.41 & 0.80 & 0.50 & 0.81 \\
\hline 5 & 0 & 1 & 0 & 1 & 0 & 1 & 0.33 & 0.88 & 0.33 & 0.88 & 0.33 & 0.88 \\
\hline mean & 0.25 & 0.96 & 0.15 & 0.92 & 0.17 & 0.95 & 0.45 & 0.73 & 0.33 & 0.80 & 0.35 & 0.84 \\
\hline
\end{tabular}


vary substantially and, although similar diagnostic parameters were utilized and operators presented different levels of experience and skills, the samples showed different prevalences of the disease and unreported occlusal surfaces with and without cavities.

Wenzel $^{28}$ (1998) suggests that laboratory diagnosis can be better than clinical diagnosis, and that the interpretation of results obtained in laboratory experiments, despite the attempt to recreate clinical conditions, may not be reliable. However, Hintze, Wenzel ${ }^{9}$ concluded, in 1996, that the clinical results of radiographic diagnoses of occlusal and proximal carious lesions were comparable to those obtained in laboratory.

Dentin may become carious on sites where the enamel is macroscopically healthy; sugar types used by bacteria as a substrate for fermentation and dentin decalcification can be taken to internal parts of teeth through the enamel. Whether or not the produced acids will cause carious lesions will depend on the buffering capacity of saliva ${ }^{25}$.

The prevalence of dentinal lesions without clinically visible cavities has been recorded as being approximately $15 \%$; however, it could reach $50 \%{ }^{13,25}$. In this study, the prevalence was $32 \%$, which is similar to that found by Ashley, et al. ${ }^{1}$ in 1998, that is, 36\% of dentinal carious lesions.

A highly sensitive and specific test is desirable; however, this is not always possible. There is a counterbalance between the sensitivity and the specificity of a diagnostic test $^{8}$. When sensitivity decreases, specificity increases and its implications for the diagnosis of carious lesions have been discussed ${ }^{2,17}$. Patients should be evaluated with regard to their potential risk to dental caries, as unnecessary treatments may be conducted on low-risk patients in case highly sensitive methods are used, since they will generate a larger number of false-positive results. Monitoring such false-positive lesions would be a wiser decision, as they will not develop ${ }^{2}$.

When high sensitivity and specificity values cannot be evaluated, a method that results in higher specificity values is preferable, since there is less risk of unnecessary treatments ${ }^{5}$.

The specificity of the Visual Inspection method presented an average of 0.96 , which was similar to that obtained by Lussi ${ }^{17}$ in 1993, that is 0.93 , as well as to that obtained by Verdonschot, et al. ${ }^{23}$, in 1992, which was 0.94 . However, it was higher than those shown by the radiographic methods (statistically significant difference to the level of $1 \%)$. The sensitivity values were lower than those of radiographic methods, although they were not statistically different.

In 1998, Ekstrand, et al. ${ }^{6}$, considering the low sensitivity of visual inspection during the low prevalence of the disease, stated that the importance of specificity is increased, and that, due to its perfect specificity, visual inspection provides a more accurate diagnosis, thus being a valid method, particularly in situations of low caries prevalence. To Wenzel ${ }^{29}$ (1993), radiography is still a significant and reasonably accurate method for groups with high caries prevalence and detection of dentinal lesions on the occlusal surface with no or little cavitation.

Regarding the videoscope methods, Longbottom and Pitts ${ }^{16}$ (1990) claims that one of their major disadvantages is the need to work on a dry field, since any amount of saliva can alter the diagnosis due to image enlargement. As this is an in-vitro study, this factor has been disregarded.

To Weerheijm, et al. ${ }^{27}$ (1989), while more effective methods for the diagnosis of occlusal carious lesions are not available, the combination of bite-wing radiography and clinical examination with a probe must be used.

According to Penning, et al. ${ }^{19}$ (1992), the probe showed to be doubtful and not very useful in the detection of fissure carious lesions. They suggest that the fact that it is still used as a diagnostic method may be due to its convenient applicability, to the lack of familiarity of professionals with other methods and to the belief that probing is a trustworthy method. They also add that methods using direct visualization and bite-wing radiography are as good as or even superior to probing with regard to sensitivity and specificity.

Weerheijm, et al. ${ }^{26}$ (1997) claim that, with the decline in caries prevalence and the change in caries development patterns due to the use of fluoride, radiographic examination is important in the diagnosis of hidden caries by contemporary professionals.

An important factor which was taken into account in this study was the depth of dentinal lesions. They were not too deep, that is, they were restricted to the dentinoenamel junction region or did not go any farther than half of its extension to the pulpal chamber. Through $\mathrm{RxC}$, three examiners identified 33\% of the sites presenting dentinal caries. Flaitz, et al. ${ }^{7}$ (1986) described that only 33\% of dentinal carious lesions were observed by bite-wing radiography of permanent posterior teeth, whereas deep lesions were thoroughly identified.

In 1993, Lussi ${ }^{17}$ suggested that dental surgeons should be taught to combine the many techniques and that, above all, they should examine bite-wing radiographs not only for proximal caries, but also for occlusal ones. According to Verdonschot, et. al. ${ }^{24}$ (1993), the radiographic method, when associated with visual inspection, does not improve the diagnosis of carious lesions in individuals belonging to populations with low caries prevalence.

Regarding the method using direct digital radiography, Ashley, et al. ${ }^{1}$ (1998) obtained sensitivity and specificity of 0.24 and 0.89 , respectively, for conventional radiography and 0.19 and 0.89 for direct digital imaging by using the Digora system. These values are similar to those in this study. To Welzel, et al. ${ }^{29}$ (1993), digital images showed to be as accurate or better than conventional radiography for the diagnosis of dentinal carious lesions on the occlusal surface of teeth with no or little cavitation. To Hintze, et al. ${ }^{10}$ (1994) and White and Yoon ${ }^{30}$ (1997), digital and conventional radiography are diagnostically compatible.

When the region of fossulae and fissures are evaluated to identify the presence of carious lesions in teeth without cavities, it is intended, if necessary, to perform the most preventive procedures. The available methods should also 
be evaluated with regard to their cost-benefit relationship. To Ie, et al. ${ }^{11}$ (1998), small differences found between visual inspection and other diagnostic methods, as well as its simplicity, would justify its use in the prediction of occlusal carious lesions.

\section{CONCLUSIONS}

1. The effectiveness of clinical methods: Visual Inspection, AccuCam and Tactile were similar and so was that of radiographic methods: CR, DR and DRcb;

2. the radiographic methods obtained a larger number of correct results concerning the presence of dentinal lesions than the clinical methods; however, when compared, they did not present statistically significant differences;

3. in general , the clinical methods obtained a smaller number of false-positive diagnoses than the radiographic methods;

4. it is suggested that bite-wing and direct digital radiography, with or without contrast and brightness control, are similar methods.

5. Visual inspection is an important method in the diagnosis of carious lesions without macroscopic cavities in populations with low caries prevalence; radiography can also help in diagnosing.

\section{ACKNOLEDGEMENTS}

Prof. Dr. Geraldo Maia Campos, Prof. Dr. Paulo Tambasco de Oliveira, Prof. Dr. José Roberto Freitas e Prof. Dra. Suzana Alves de Moraes.

\section{REFERENCES}

1- Ashley PF, Blinkhorn AS, Davies RM. Occlusal caries diagnosis: an in vitro histological validation of the Eletronic Caries Monitor (ECM) and other methods. J Dent 1998 Mar;26(2):83-8.

2- Benn DK. Radiographic caries diagnosis and monitoring. Dentomaxillofac Radiol 1994 May;23(2):69-72.

3- Clark DC, Hann HJ, Williamson MF, Berkowitz J. Effects of lifelong consumption of fluoridated water or use of fluoride supplements on dental caries prevalence. Community Dent Oral Epidemiol 1995 Feb;23(1):20-4.

4- Deery C, Fyffe HE, Nugent Z, Nuttall NM, Pitts NB. The effect of fissure sealant on the validity and reproducibility of occlusal caries diagnosis. Caries Res 1995 Sept/Oct;29(5):377-381.

5- Ekstrand K, Qvist V, Thylstrup A. Light microscope study of the effect of probing in occlusal surfaces. Caries Res 1987 July/ Aug;21(4):368-374.

6- Ekstrand K, Ricketts DNJ, Kidd EAM, Qvist V, Schou S. Detection, diagnosing, monitoring and logical treatment of occlusal caries in relation to lesion activity and severity: an in vivo examination with histological validation. Caries Res 1998 July/Aug;32(4):247-54.

7- Flaitz CM, Hicks MJ, Silverstone LM. Radiographic, histological and eletronic comparison of occlusal caries: an in vitro study. Pediatr Dent 1986 Mar;8(1):24-8.
8- Fletcher RH, Fletcher SW, Wagner EH. Diagnóstico. In: Epidemiologia clínica: elementos essenciais. $3^{\text {th }}$ ed. Porto Alegre: Artes Médicas; 1996. p.52-83

9- Hintze H, Wenzel A. Clinical and laboratory radiographic caries diagnosis: a study of the same teeth. Dentomaxillofac Radiol 1996 June;25(3):115-8.

10- Hintze H, Wenzel A, Jones C. In vitro comparison of ad- and Espeed film radiography, RVG, and visualix digital radiography for the detection of enamel proximal and dentinal occlusal caries lesions. Caries Res 1994 Sept/Oct;28(5):363-7.

11- Ie YL, Verdonschot EH, Van’t Hof MA. Performance of some diagnostic systems in the prediction of occlusal caries in permanent molars in 6- and 11-year-old children. J Dent 1998 July/Aug;26(5/ 6):403-8

12- Ismail AI. Clinical diagnosis of precavitated carious lesions. Community Dent Oral Epidemiol 1997 Feb;25(1):13-23.

13- Kidd EAM, Naylor MN, Wilson RF. Prevalence of clinically undetected and untreated molar occlusal dentine caries in adolescents on the Isle of Wright. Caries Res 1992 Sept/Oct;26(5):397-401.

14- Kidd EAM, Ricketts DNJ, Pitts NB. Occlusal caries diagnosis: a changing challenge for clinicians and epidemiologists. J Dent 1993.Dec; 21(6): 323-37.

15- Landis J, Koch G. The measurement of observer agreement of categorical data, Biometrics 1977; 33:159-74.

16- Longbottom C, Pitts NB. An initial comparison between endoscopic and conventional methods of caries diagnosis. Quintessence Int 1990 July;21(7):531-40.

17- Lussi A. Comparison of different methods for the diagnosis of fissure caries without cavitation. Caries Res 1993 Sept/Oct;27(5):40916

18- Lussi A. Validity of diagnostic and treatment decisions of fissure caries. Caries Res 1991 July/Aug;25(4):296-303.

19- Mestriner Júnior W, Polizello ACM, Spadaro ACC. Enamel fluoride concentrations in unerupted third molars and the influence of fluoridated water on caries scores. Caries Res 1996 Jan/ Feb;30(1):83-7.

20- Penning C, Van Amerogen JP, Seef RE, Ten Cate JM. Validity of probing for fissure caries diagnosis. Caries Res 1992 Nov/ Dec;26(6):445-9.

21- Pitts NB, Longbottom C. The use of endoscopically viewed filtered fluorescence for the clinical diagnosis of caries lesions in dental enamel. Med Sci Res 1987v Apr./June;15(7-12):535-6.

22- Richetts DNJ, Kidd EAM, Beighton D. Operative and microbiological validation of visual, radiographic and electronic diagnosis of occlusal caries in non-cavitated teeth judged to be in need of operative care. Br Dent J 1995 Sept;1(6):214-220.

23- Verdonschot EH, Bronkhorst EM, Burgersdijk RCW, König KG, Schaeken MJM, Truin GJ. Performance of some diagnostic systems in examinations for small occlusal carious lesions. Caries Res 1992 Jan./Feb;26(1):59-64.

24- Verdonschot EH, Wenzel A, Truin GJ, König KG. Performance of electrical resistance measurements adjunct to visual inspection in the early diagnosis of occlusal caries. J Dent 1993 Dec; 21(6):332-7.

25- Weerheijm KL, Groen HJ, Bast AJJ, Kieft JA, Eijkman MAJ, Van Amerongen WE. Clinically undetected occlusal dentine caries: a radiographic comparison. Caries Res 1992 July/Aug;26(4):305-9. 
26- Weerheijm KL, Kidd EAM, Groen HJ. The effect of fluoridation on the occurrence of hidden caries in clinically sound occlusal surfaces. Caries Res 1997 Jan./Feb;31(1):30-4.

27- Weerheijm KL, Van Amerongen EW, Eggink OC. The clinical diagnosis of occlusal caries: a problem. ASDC J Dent Child 1989 May/June;196(3):196-200.

28- Wenzel A. Digital radiography and caries diagnosis (review). Dentomaxillofac Radiol 1998 Jan;27(1):3-11.

29- Wenzel A. New caries diagnostic methods. J. Dent Educ 1993 June;57(6):428-32.

30- White GE, Yoon DC. Comparative performace of digital and convencional images for detecting proximal surface caries. Dentomaxillofac Radiol 1997 Jan;21(1):32-8. 